\title{
Standards for libraries in higher education
}

\section{The nal, approved standard}

\author{
by the ACRL College and Research Libraries Task Force
}

\section{Preface}

These standards differ from earlier ACRL library standards in four signi cant respects.

1. They are intended to apply to all types of libraries in higher education, from technical institutes to research universities.

2. The standards and key principles are designed as a tool to help libraries establish individual goals within the context of their institutional goals.

3. They focus on documenting the library s contribution to institutional effectiveness and student learning outcomes

4 . The standards provide suggested points of comparison for peer and longitudinal comparison and encourage the development of other measures. Some measures of quality and quantity are used in this document, as well as questions to provide guidance for assessing each element of library operations and the provision of library services.

To be applicable to such a wide range of libraries, it is necessary that the standards not be prescriptive. Instead, they provide a comprehensive outline to methodically examine and analyze all library operations, services, and outcomes in the context of accreditation. The expectation is that these standards embrace key principles that will continue to be espoused by regional accrediting associations as critical elements or core requirements that provide a foundation upon which a library documents its compliance.

The standards refer to other speci c ACRL guidelines and standards developed to address specialized operations and initiatives (for example, Guidelines for distance learning library services, Information literacy competency standards for higher education, and Guidelines for media resources in academic libraries ). The committee recognizes that not all variations in types of collections or services are directly addressed in the Standards. Without incorporating such speci cs directly into this document, it is anticipated that there would be less need for its frequent revision. It is expected that ACRL standards and guidelines, both existing and those developed later, as well as standards from other organizations, can be used as part of a library s analytical structure as appropriate.

\section{Foreword}

These standards are intended to apply to libraries supporting academic programs at institutions of higher education. Earlier standards for libraries relied heavily upon resource and program inputs, such as nancial support, space, materials, and staff activities. These new standards continue to consider inputs, but they also take into consideration outputs and outcomes. In 


\section{Development and approval of the standards}

These standards supersede earlier separate library standards produced by ACRL s CLS, CJCLS, and ULS. The rst edition of the college library standards was published in 1959; subsequent editions were published in 1975 , 1986, 1995, and 2000. Standards for two-year institutions were rst published in 1960 and revised in 1979, 1990, and 1994. Standards for university libraries were rst issued in 1979 and revised in 1989. (1a)

In 1998, on the recommendation of the Task Force on Academic Library Outcomes Assessment, the ACRL Board mandated that all future standards incorporate outcomes assessment. The 2000 edition of Standards for college libraries was the rst to incorporate outcomes assessment and was considered a model for the other two library standards. Representatives from the standards committees of the CLS, CJCLS, and ULS met and eventually recommended that the new college library standards be adapted as a single comprehensive standard for use by all academic and technical libraries. ACRL formed a task force in 2002 to accomplish this task.

The College and Research Libraries Standards Task Force produced a draft document that was widely circulated on electronic discussion lists, printed in CERL News, and published on the ACRL Web page. Review of the draft was encouraged by e-mail to members, comments by an expert, and through public hearings at the ALA conferences in Toronto (June 2003) and San Diego (January 2004). A revised draft was then published on the Web site for additional comment. In June 2004, the
ACRL Standards and Accreditation Committee and the ACRL Board approved the nal document, and the three extant library standards were rescinded.

This document and additional information about ACRL s standards and guidelines may be found at www.ala.org/ala/acrl/acrlstandards/ standardsguidelines.htm.

\section{Note}

(1a) William N. Nelson, Library Standards in Higher Education: An Overview, Encyclopedia of Library and Information Science. Published online July 21, 2004, www.dekker.com/servlet/product/DOI /101081EELIS120021360 (last accessed 8/26/2004).

\section{About the authors}

Members of the Task Force on Academic Library Outcomes Assessment who were responsible for the preparation of these standards were: Chair, Barton M. Lessin, Wayne State University, e-mail: lessin@wayne.edu; Mary M. Carr, Spokane Community College, e-mail: mcarr@scc.spokane.edu; Robert W. Fernekes, Georgia Southern University, email: Fernekes@georgiasouthern.edu; Lori A. Goetsch, University of Maryland, e-mail: lgoetsch@lib.ksu.edu; David W. Lewis, Indiana University-Purdue University Indianapolis, e-mail: dlewis@iupui.edu; Ellen J. Meltzer, University of California California Digital Library, e-mail: ellen.meltzer@ucop. edu; William N. Nelson, Augusta State University, e-mail: wnelson@aug.edu; and Cary L. Sowell, Austin Community College, e-mail: cary@austincc.edu. order to create uniformity, the de nitions as described in the ACRL Task Force on Academic Library Outcomes Assessment Report will be used in these standards.

Inputs are generally regarded as the raw materials of a library program the money, space, collection, equipment, and staff, out of which a program can arise.
Outputs serve to quantify the work done, i.e., number of books circulated, number of reference questions answered.

Outcomes are the ways in which library users are changed as a result of their contact with the library s resources and programs. ${ }^{2}$

These standards provide both a quantitative and a qualitative approach to assessing 
the effectiveness of a library and its librarians. They advocate the use of input, output, and outcome measures in the context of the institution s mission statement. They encourage comparison of these measures with those of peer institutions; they provide statements of good library practice; and they suggest ways to assess that practice in the context of the institution s priorities. They address libraries only, not other components of a larger organization (e.g., computing).

In considering the application of these standards, those who make use of them should keep in mind the rapid changes in scholarly communication that have taken place in recent years. While electronic publications have increased in number, publications on paper and microtext have continued, making it necessary for librarians to store, provide, and interpret information in multiple formats. With the increase in the availability of information, user expectations have risen substantially. Librarians are increasingly expected to assist users in evaluating the information they receive. These changes evince an evolving role for librarians, one that suggests a closer partnership with users and a greater responsibility for the educational process.

\section{Points of comparison}

Each library is encouraged to choose its own peer group for the purpose of comparisons. Peer groups may already be identi ed for benchmarking purposes by the institution. If not, a peer group could be identi ed using criteria such as the institution s mission, reputation, selectivity for admission, size of budget, size of endowment, expenditure for library support, and/or size of collection. Once a peer group has been determined, points of comparison can be made to compare the strength of the library with its peers. Suggested points of comparison for input and output measures are provided. This list is not to be considered exhaustive; other points of comparison can be determined by the institution. If comparisons are going to be conducted on an annual or other regular basis, the same categories should be used each time to assure a consistent and usable result.

\section{Suggested points of comparison: Input measures}

Ratio of volumes to combined total student (undergraduate and graduate, if applicable) and faculty FTE.

Ratio of volumes added per year to combined total student and faculty FTE.

Ratio of material/information resource expenditures to combined total student and faculty FTE.

Percent of total library budget expended in the following three categories:

1. materials/information resources, subdivided by print, microform, and electronic.

2. staff resources, subdivided by librarians, full- and part-time staff, and student assistant expenditures. Federal contributions, if any, and outsourcing costs should be included here. When determining staff expenditures, care should be taken to consider comparable staff (i.e., including or excluding media, systems, or development staff) and fringe bene ts (within or outside the library budget).

3. all other operating expenses (e.g., network infrastructure, equipment).

Ratio of FTE library staff to combined student and faculty FTE.

Ratio of usable library space (in square feet) to combined student and faculty FTE.

Ratio of number of students attending library instructional sessions to total number of students in speci ed target groups. ${ }^{3}$

Ratio of library seating to combined student and faculty FTE. ${ }^{4}$

Ratio of computer workstations to combined student and faculty FTE (consider that institutional requirements for student ownership of desktop or laptop computers could affect the need for workstations within the library).

\section{Suggested points of comparison: Output measures \\ Ratio of circulation (excluding reserve) to combined student and faculty FTE.}


Ratio of interlibrary loan requests to combined student and faculty FTE (could be divided between photocopies and books).

Ratio of interlibrary loan lending to borrowing.

Interlibrary loan/document delivery borrowing turnaround time, ll rate, and unit cost.

Interlibrary loan/document delivery lending turnaround time, 11 rate, and unit cost.

Ratio of reference questions (sample week) to combined student and faculty FTE.

\section{Planning, assessment, and outcomes assessment \\ Planning}

The library should have a mission statement and goals to serve as a framework for its activities. The mission and goals should be compatible and consistent with those developed by the institution. Assessment of the quality and effectiveness of the library should be linked closely with the speci c mission and goals of the institution. In order to build its programs and services in the context of the institution, the library should be involved in the overall planning process. Formal planning procedures and methods, such as strategic planning, are used frequently. These planning methods require input from a broad spectrum of the institution s community. They help the institution prepare for the future by clearly de ning a vision and mission, by setting goals and objectives, and by implementing speci c strategies or courses of action designed to help meet those ends. Strategic planning is an iterative process that includes evaluation, updating, and re nement. This process helps the community focus on its essential values and provides an overall direction that helps to guide day-today activities and decisions. ${ }^{5}$

\section{Assessment}

Comprehensive assessment requires the involvement of all categories of library users and also a sampling of non-users. The choice of clientele to be surveyed and questions to be asked should be made by the administration and the staff of the library with the assistance of an appropriate advisory committee. Questions should relate to how well the library supports its mission and how well it achieves its goals and objectives. Library users should be encouraged to offer signed or anonymous comments and suggestions. Opportunities for making suggestions should be available both in the library and through remote electronic access. All categories of users should be given an opportunity to participate in the evaluation. The weight given to responses should be consistent with the focus and mission of the library. A program of assessment and evaluation should take into consideration the changing rhythm of the academic year. Evaluation, whether it involves some or all of the techniques listed below, should be an ongoing process. Formal evaluation tools may include the following:

General library knowledge surveys (or pre-tests ) offered to incoming rst-year students, re-offered at a midpoint in the students careers and again near graduation, to assess whether the library s program of curricular instruction is producing more information-literate students.

Evaluation checklists for librarian and tutorial instruction to gather feedback from students, other librarians, and teaching faculty.

Student journal entries, or information literacy diaries, used to track their library use.

Focus groups of students, faculty, staff, and alumni who are asked to comment on their experiences using information resources over a period of time.

Assessment and evaluation by librarians from other institutions and/or other appropriate consultants.

Reviews of speci c library and information service areas and/or operations.

\section{Outcomes assessment}

Outcomes assessment will increasingly measure and affect how library goals and 
objectives are achieved. It will address the accountability of institutions of higher education for student achievement and cost effectiveness. It should take into consideration libraries greater dependence on technology, their increasing use of online services, their growing responsibility to provide information literacy skills, their increasing reliance on consortial services, the possibilities of dwindling nancial resources for collection development, and new developments in the ways in which scholarly information is published and distributed.

Outcomes assessment can be an active mechanism for improving current library practices. It focuses on the achievement of outcomes that have been identi ed as desirable in the library s goals and objectives. It identi es performance measures, such as prociencies, that indicate how well the library is doing what it has stated it wishes to do.

Assessment instruments may include surveys, tests, interviews, and other valid measuring devices. These instruments may be specially designed for the function being measured, or previously developed instruments may be used. It is critical, however, to choose carefully the instrument, the size of the sample, and the method used for sampling. The instrument should be valid, and the way it is used should be appropriate for the task. Colleagues at peer institutions may render invaluable assistance by suggesting assessment questions and sample sizes, by sharing lessons learned, and suggesting alternative methods for measuring outcomes.

\section{Questions}

1. Is the library s mission statement clearly understood by the library staff and the institution s administration? Is it reviewed periodically?

2. How does the library incorporate the institution s mission into its goals and objectives?

3. How does the library maintain a systematic and continuous program for evaluating its performance, for informing the institution s community of its accomplishments, and for identifying and implementing needed improvements?

4. Is the librarys assessment plan an integral component of the institution $s$ assessment and accreditation strategies? For example, does the library revise and update its assessment procedures in conjunction with campus-wide planning and the actions of academic departments?

5. How does the library assess itself? (e.g., What quantitative and qualitative data does the library collect about its performance? How does it take into account special needs, such as those of physically challenged users?)

6. What outcomes does the library measure, and how does it measure these outcomes?

7. How does the library compare itself with its peers?

\section{Services}

The library should establish, promote, maintain, and evaluate a range of quality services that support the institution $s$ mission and goals. The library should provide competent and prompt assistance for its users. Hours of access to the library should be reasonable and convenient for its users. Reference and other special assistance should be available at times when the institution s primary users most need them.

\section{Questions}

1. How well does the library establish, promote, maintain and evaluate a range of quality services that support the academic program of the institution and optimal library use?

2. Are reference, circulation, and government document services designed to enable users to take full advantage of the resources available to them?

3. How do student and faculty expectations affect library services?

4. How well do interlibrary loan and document delivery services support the needs of quali ed users? 
5. Does the library maintain hours of access consistent with reasonable demand?

6. What library services are provided for programs at off-campus sites? How are the needs of users and their satisfaction determined at those sites?

7. How are students and faculty informed of library services?

8. Does the library maintain and utilize quantitative and qualitative measurements of its ability to serve its users?

9. When academic programs are offered at off-campus sites, what are the standards or guidelines used to assure success? Are the ACRL Guidelines for distance learning library services (www.ala.org/acrl/guides/ distlrng.html) used to consider existing and potential services?

\section{Instruction}

The library should provide information and instruction to users through a variety of reference and user education services, such as course-related and course-integrated instruction, hands-on active learning, orientations, formal courses, tutorials, path nders, and point-of-use instruction, including the reference interview.

As an academic or instructional unit within the institution, the library should facilitate student success, as well as encourage lifelong learning. By combining new techniques and technologies with the best of traditional sources, librarians should assist primary users and others in information retrieval methods, evaluation, and documentation.

In addition, librarians should collaborate frequently with classroom faculty; they should participate in curriculum planning and information literacy instruction as well as educational outcomes assessment. Information literacy skills and user education should be integrated across the curriculum and into appropriate courses with special attention given to information evaluation, critical thinking, intellectual property, copyright, and plagiarism.
Modes of instruction, often referred to as teaching methods, may include, but are not limited to advising individuals at reference desks, in-depth research consultations, individualized instruction, electronic or print instruction aids, or group instruction in traditional or electronic classroom settings. ${ }^{6}$

\section{Questions}

1. Does the library provide formal and informal opportunities for instruction?

2. Does the library provide adequate space for instruction for both large and small groups? Is the available space designed to provide hands-on instruction, as well as presentation of all types of resources?

3. Does the library make appropriate use of technology in its instruction?

4. How do librarians work with classroom faculty in developing and evaluating library curricula in support of speci $\mathrm{c}$ courses?

5. If applicable, how does the library facilitate faculty research?

6. Does the library provide a variety of educational programs?

7. How does the library promote and evaluate its instructional programs?

8. How does the library apply the Information literacy competency standards for higher education?

\section{Resources}

The library should provide varied, authoritative and up-to-date resources that support its mission and the needs of its users. Resources may be provided onsite or from remote storage locations, on the main campus, and/or at off-campus locations. Moreover, resources may be in a variety of formats, including print or hard copy, online electronic text or images, and other media. Within budget constraints, the library should provide quality resources in the most ef cient manner possible. Collection currency and vitality should be maintained through judicious weeding. 


\section{Questions}

1. What criteria are used to make decisions about the acquisition, retention, and use of print, electronic, and media resources? How does the library select resources for its users?

2. What is the role of the classroom faculty in the selection of library resources and in the ongoing development and evaluation of the collection?

3. Does the library have a continuing and effective program to evaluate its collections, resources and online databases, both quantitatively and qualitatively?

4. Do print, media, and electronic resources re ect campus curricular and research needs?

5. Does the library have suf cient user licenses for its electronic resources so that on-site and remote users can be accommodated?

6. How are consortium purchasing and licensing agreements utilized?

7. If the library has responsibility for collecting and maintaining the institution $s$ archives, how does it address these responsibilities?

8. How do the library s collections and online databases compare with its peers?

9. Does the library maintain the currency and relevancy of the collection through a judicious weeding program?

\section{Access}

Access to library resources should be provided in a timely and orderly fashion. Library collections and the catalog for accessing them should be organized using national bibliographic standards. A central catalog of library resources should provide access for multiple concurrent users and clearly indicate all resources. Provision should be made for interlibrary loan, consortial borrowing agreements, access to virtual electronic collections, and document delivery to provide access to materials not owned by the library.

Furthermore, distance learning programs should be supported by equivalent means, such as remote electronic access to collections, the provision of reliable network connections, and electronic transmission or courier delivery of library materials to remote users. Policies regarding access should be appropriately disseminated to library users.

\section{Questions}

1. What methods are used to provide maximum intellectual and physical accessibility to the library and its resources?

2. How are the accuracy and currency of the catalog assured?

3. Is the arrangement of the collections logical and understandable?

4. Does the library provide timely and effective interlibrary loan or document delivery service for materials not owned by the library?

5. Does the library participate in available consortial borrowing programs?

6. Does the library provide suf cient numbers of appropriately capable computer workstations for access to electronic resources?

7. Is access to the catalog and to other library resources available across campus and off-campus?

8. If materials are located in a storage facility, are those materials readily accessible?

9. In what ways does the library provide for its users who are engaged in distance learning programs?

\section{Staff}

The staff should be suf cient in size and quality to meet the programmatic and service needs of its primary users. Librarians should have a graduate degree from an ALA-accredited program. In addition, there may be other professional staff who will have appropriate combinations of training, experience, and/or degrees. All library professionals should be responsible for and participate in professional activities. The support staff and student assistants should be assigned responsibilities appropriate to their quali cations, training, 
experience, and capabilities. The further development of professional and support staff should be promoted through an ongoing commitment to continuing education, including training on security, emergencies, and the preservation of materials.

Professional library staff should be covered by a written policy that clearly establishes their status, rights, and responsibilities. This policy should be consistent with the ACRL Standards for faculty status for college and university librarians (www.ala. org/acrl/guides/facstat01.html).

\section{Questions}

1. Does the library employ staff capable of supporting and delivering information in all available formats, including electronic resources?

2. Is suf cient budgetary support provided to ensure the ongoing training of all staff?

3. Does the library have quali ed librarians, other professional staff, skilled support staff, and student assistants in adequate numbers to meet its needs? Counts may include FTE library staff numbers for total staff and a separate number for FTE librarians (MLS or equivalent).

4. How does the institution ensure that the library s professional staff have the appropriate accredited degrees, and how does it encourage them to engage in appropriate professional activities?

5. How does the size of the library staff relate to the goals and services of the library, the institution $s$ programs, degrees, enrollment, size of the faculty and staff, and auxiliary programs?

6. How do library staff policies and procedures compare with institutional guidelines and sound personnel management, especially in the areas of recruitment, hiring, appointment, contract renewal, promotion, tenure, dismissal, and appeal?

7. How do staff members who are responsible for instruction maintain suf cient knowledge and skills to be effective instructors?

8. How does the library provide security and emergency training for its staff?

\section{Facilities}

The library facility and its branches should be well planned; it should provide secure and adequate space, conducive to study and research with suitable environmental conditions for its services, personnel, resources, and collections. The librarys equipment should be adequate and functional.

\section{Questions}

1. Does the library provide well-planned, secure, and suf cient space to meet the perceived needs of staff and users?

2. Are building mechanical systems properly designed and maintained to control temperature and humidity at recommended levels?

3. What are the perceptions of users regarding the provision of conducive study spaces, including a suf cient number of seats and varied types of seating?

4 . Is there enough space for current library collections and future growth of print resources?

5. Does the staff have suf cient workspace, and is it configured to promote ef cient operations for current and future needs?

6. Does the library s signage facilitate use and navigation of the facilities?

7. Does the library provide ergonomic workstations for its users and staff?

8. Are electrical and network wiring sufcient to meet the needs associated with electronic access?

9. Does the library meet the requirements of the Americans with Disabilities Act?

10. Are facilities provided to distance learners considered in the context of the ACRL Guidelines for distance learning and library services (www.ala.org/acrl/guides /distlrng.html)?

\section{Communication and cooperation}

Communication is essential to ensure the smooth operation of the library. Communication should ow from all levels of the library: from the director/dean to the staff and from the staff to the director/dean. 
The library should have a regular mechanism to communicate with the campus.

Library staff should work collaboratively and cooperatively with other departments on campus. A special relationship should be encouraged between the library and information technology staff in providing access to electronic information resources. In some cases, a vice-president, dean, or director may administer library, media, and information technology operations and services.

The library is usually responsible for selecting and providing information content. Information technology usually provides the technical infrastructure and support to deliver information. There is no single organizational model that will work for all institutions. Regardless of whether the services are independent or are integrated in some way, it is important that the services work collaboratively and keep each other fully informed.

\section{Questions}

1. Is there effective communication within the library that allows for a free flow of administrative and managerial information?

2. Are staff members encouraged to suggest new ideas or procedures to improve operations or working conditions within the library? Is there a process to facilitate this?

3. Does the library have a regular means to exchange information with the campus?

4. Has the library established cooperative working relationships with other departments on campus?

5. If the library and information technology are administered separately, does the organizational structure provide opportunities for productive communication and collaboration?

6. If one administrator has responsibility for both the library and information technology, how well have the two functions been integrated?
7. Is the library able to obtain technical support for information technology in the form of in-house expertise to provide electronic resources to on-site and remote users?

8. Is the capacity of the campus network suf cient to provide reasonable response times for local and remote information resources?

\section{Administration}

The library should be administered in a manner that permits and encourages the most effective use of available library resources. The library director/dean should report to the president or to the appropriate chief academic or instructional officer of the institution. There should be a standing library advisory committee. The responsibilities and authority of the library director/dean should be defined in writing.

If there are distance learning services provided, they should be administered in keeping with the suggestions offered in the ACRL Guidelines for distance learning library services. The library should be administered in accordance with the spirit of the ALA Library Bill of Rights.

\section{Questions}

1. How does the library administration encourage effective use of available library resources?

2. What is the statutory or legal foundation (e.g., institutional bylaws) for the library s activities?

3. To whom does the library director/ dean report? Is that reporting relationship appropriate?

4. Is there a document that de nes the responsibilities and authority of the library director/dean?

5. Does the library have a standing advisory committee? Does the committee have adequate classroom faculty and student representation? How effective is the committee? 
6. How effective are the policies and procedures that determine internal library governance and operations?

7. Does the library operate in accord with the spirit of the ALA Library Bill of Rights ?

\section{Budget}

The library director/dean should prepare, justify, and administer a library budget that is appropriate to the library s objectives. The budget should meet the reasonable expectations of library users when balanced against other institutional needs. The library should utilize its nancial resources ef ciently and effectively. The library director/dean should have authority to apportion funds and initiate expenditures within the library budget and in accordance with institutional policy. The budget should support appropriate levels of staf ng and adequate staff compensation.

\section{Questions}

1. Does the library director/dean prepare, justify, and administer the library budget in accordance with agreed upon objectives?

2. Are the librarys annual authorized expenditures adequate to meet the ongoing, appropriate needs of the library?

3. How is the institution s curriculum taken into account when formulating the library s budget?

4. How are the instructional methods of the institution, especially as they relate to independent study, considered when formulating the library s budget?

5. What methods are used to determine the adequacy of existing collections? Is the budget adequate to maintain an appropriate rate of collection development in elds pertinent to the curriculum?

6. How does the size, or anticipated size, of the student body and the classroom faculty affect the library budget?

7. Does the budget support an appropriate level of staf ng and compensation?
8. How is the adequacy and availability of funding for other library resources (e.g., archives and special collections) determined?

9. Does the library budget re ect the library s responsibility for acquiring, processing, servicing, and providing access to media and computer resources?

10. To what extent does the library director/dean have authority to apportion funds and initiate expenditures within the library budget and in accordance with institutional policy?

11. How does the library monitor its encumbrances and the payment of its invoices? How does the library determine its choices and schedule its expenditures?

12. Does the budget include adequate support for extended campus programs?

\section{Notes}

1. By ACRL Board action on June 29, 2004, the present document supercedes the following standards: College library standards, 2000 edition (CERL News, March 2000, p. 175 182); Standards for community, junior, and technical college learning resources programs, 1994 (CERL News, October 1994, p. 572 585); and Standards for university libraries: Evaluation of performance, 1989 (CERL News, September 1989, p. 679 691).

2. ACRL Task Force on Academic Library Outcomes Assessment, 27 June 1998, www. ala.org/acrl/outcome.html.

3. Ibid, p. 4.

4. For a further discussion of space requirements, refer to: Keyes D. Metcalf, Planning Academic and Research Library Buildings, 3rd ed. Philip D. Leighton and David C. Weber, eds. (Chicago: American Library Association, 1999, c2000). Appendices $\mathrm{B}$ and $\mathrm{C}$.

5. Regional and subject-based accrediting association guidelines can help direct the institution in its planning and assessment.

6. ACRL Guidelines for instruction programs in academic libraries, www.ala. org/acrl/guides/guiis.html. 